\title{
Dentoalveolar Segmental Osteotomy Combined with Orthodontic Treatment for an Impacted and Ankylosed Upper Canine: A Case Report
}

\author{
Hanna Cecilia Aludden, Thomas Jensen \\ Department of Oral and Maxillofacial Surgery, Aalborg University Hospital, Aalborg, Denmark \\ Email: h.aludden@rn.dk, thomas.jensen@rn.dk
}

Received 29 December 2015; accepted 4 April 2016; published 7 April 2016

Copyright (C) 2016 by authors and Scientific Research Publishing Inc.

This work is licensed under the Creative Commons Attribution International License (CC BY). http://creativecommons.org/licenses/by/4.0/

(c) (i) Open Access

\begin{abstract}
Ankylosis is the abnormal adhesion of alveolar bone to dentin or cementum and commonly seen after traumatic dental injuries. Treatment of impacted and ankylosed teeth solely by orthodontics alignment may be challenging. Consequently, several treatment alternatives have been proposed for the management of ankylosed teeth involving extraction, surgical luxation, and osteotomy followed by dentoalveolar distraction or conventional orthodontic treatment. This case report describes a 55-year-old female who was referred by her orthodontist due to an impacted and ankylosed maxillary upper left canine. A dentoalveolar segmental osteotomy with immediate repositioning of an upper canine was performed. One year after final orthodontic treatment a satisfying occlusal and esthetic treatment outcome was obtained.
\end{abstract}

Keywords

Ankylosis, Osteotomy, Tooth Ankylosis

\section{Introduction}

Tooth ankylosis is an anomalous eruption characterized by localized fusion of cementum and surrounding alveolar bone with obliteration of the periodontal ligament. It is apparently caused by mechanical, thermal or metabolic trauma to the periodontal membrane during or after tooth eruption [1]. Traumatic dental injuries, especially avulsion of teeth may cause tooth ankylosis [2] [3]. An ankylosed tooth is immobile and frequently infraoccluded with a high metallic percussion tone. Radiographically, tooth ankylosis is characterized by the absence 
of periodontal ligament space and continuous replacement of root substance with bone until little or no tooth substance remains.

An impacted and ankylosed tooth in infraocclusion may compromise the function and facial esthetic of the patient. Thus, several treatment modalities have been advocated for the management of an impacted and ankylosed tooth comprising extraction and prosthetic rehabilitation, surgical luxation of the tooth followed by orthodontic traction or dentoalveolar segmental osteotomy followed by dentoalveolar distraction or conventional orthodontic treatment. However, extraction of an ankylosed tooth often leads to a huge bony defect, which may need bone augmentation with autogenous bone graft from the mandibular ramus or iliac crest [4]. Moreover, dentoalveolar segmental osteotomy followed by dentoalveolar distraction will require patient cooperation and increase the total treatment time and cost. Consequently, single-tooth segmental osteotomy with immediate placement of the segment in the correct dental position will from a clinical perspective be an advantage, since the total treatment time and morbidity will be decreased.

The purpose of this case report is to describe the treatment of an impacted and ankylosed upper maxillary canine using segmental osteotomy with immediate repositioning of the tooth and to summarize the current knowledge about this treatment modality.

\section{Case Report}

A 55-year-old female was referred by her orthodontist due to an impacted and ankylosed maxillary upper left canine. Due to obvious clinical and radiographic signs of ankylosis, no attempt was made to align the upper left maxillary canine. Instead prior orthodontic treatment intended to created space for later extraction of the ankylosed tooth followed by implant placement and prosthetic rehabilitation. The patient had no history of dental trauma injury and was in good general health with no allergies or medication.

Clinical examination showed full-fixed orthodontic appliance with brackets and archwires in both upper and lower jaw. The upper left maxillary canine was partially erupted and infraoccluded compared to the adjacent lateral incisor (Figure 1). The tooth was asymptomatic with an ankylotic metallic percussion tone. There was no clinical sign of discoloration and the canine showed positive response to electric pulp test.

Panoramic and intraoral periapical radiographs of the maxillary upper left canine revealed bony impaction with lack of periodontal ligament. There was no apical pathology and sufficient interradicular space between the adjacent teeth (Figure 2).

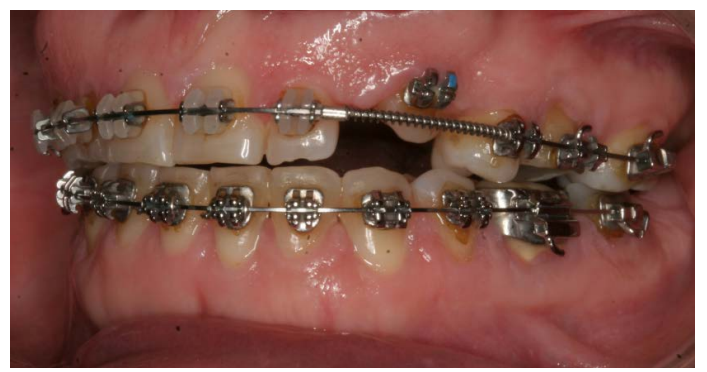

Figure 1. Pre-operative clinical examination. The upper left maxillary canine was partially erupted and infraoccluded compared to the adjacent lateral incisor.

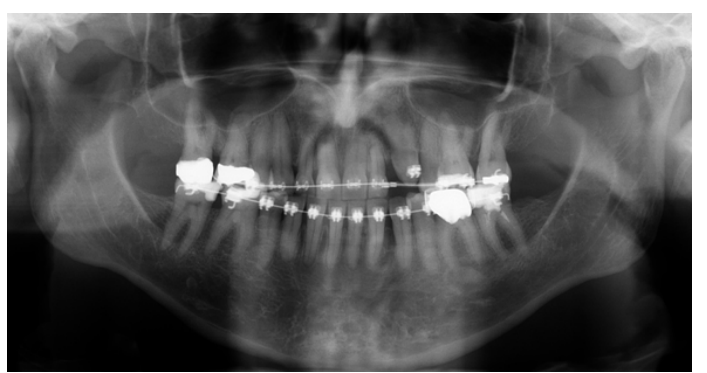

Figure 2. Panoramic radiograph of the maxillary upper left canine revealed bony impaction with lack of periodontal ligament. There was no apical pathology and sufficient interradicular space between the adjacent teeth. 
In collaboration with the orthodontist we decided to make a dentoalveolar segmental osteotomy with immediate repositioning of the tooth in neutral canine relation. The surgical procedure was performed in general anesthesia with a nasotracheal intubation. A vestibular incision was made in the unattached mucosa from the left maxillary incisor to the left second premolar. The mucoperiosteum was reflected exposing the anterior maxilla. A vertical osteotomy was made mesial and distal for the left maxillary canine with fissure bur. The two vertical osteotomies were combined with a horizontal osteotomy $5 \mathrm{~mm}$ above the root apex of the impacted canine. The osteotomy was completed with a chisel and the dentoalveolar segment was separated from the maxilla. The dentoalveolar segment including the left maxillary canine was mobilized and bonded to the orthodontic arch in the correct dental arch position (Figure 3). The wound was closed with sutures. The healing was uneventful and sutures were removed after one week. Further active orthodontic treatment was initiated to finalize the occlusion.

Orthodontic appliance were removed one year after surgery. Clinical and radiographic examination revealed a satisfying esthetic outcome with a neutral canine relation and no radiographic pathology, 18 months after surgery (Figure 4 and Figure 5).

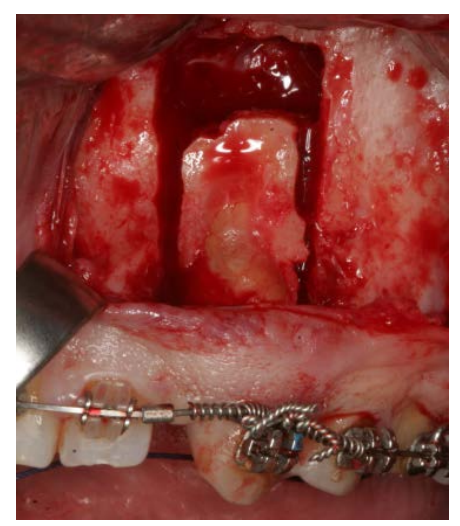

Figure 3. The dentoalveolar segment including the left maxillary canine was mobilized and bonded to the orthodontic arch in the correct dental arch position.

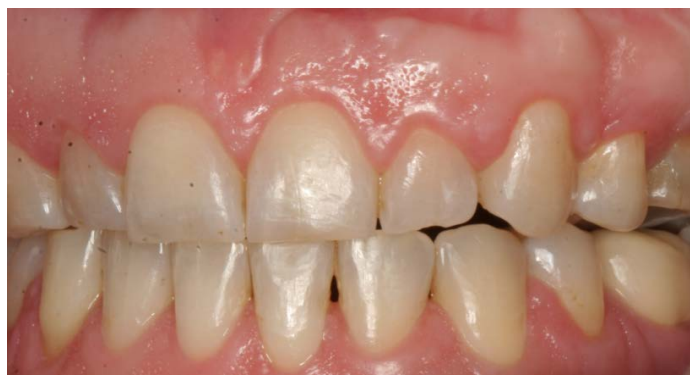

Figure 4. Clincal examination 18 months postoperatively revealed a satisfying esthetic outcome with a neutral canine relation.

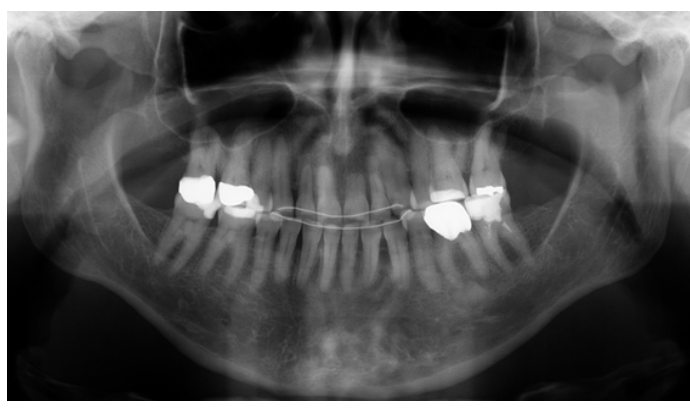

Figure 5. Radiographic examination 18 months postoperatively revealed no radiographic pathology. 


\section{Discussion}

Treatment of a 55-year-old woman with an impacted an ankylosed upper maxillary canine using dentoalveolar segmental osteotomy with immediate repositioning of the tooth was described in the present case report. An autogenous bone block including the ankylosed canine was released and replanted in the correct position where it was fixed to the orthodontic appliance during healing. The orthodontic alignment was finalized and the ankylosed canine showed no clinical or radiographic pathology after 18 months.

Dentoalveolar segmental osteotomy with immediate repositioning of the tooth or the bony segment has been used in combination with other surgical procedures including orthognatic surgery [5]-[17]. However, a review of the English literature has disclosed only four published case reports solely using dentoalveolar segmental osteotomy with immediate repositioning of the tooth as a treatment option for impacted and ankylosed teeth (Table 1). This treatment modality has only been reported for ankylosed teeth in the maxilla demonstrating satisfying short-term clinical and radiographic results comprising normal pulpal vitality and a good esthetic and functional occlusion [18]-[21].

All four cases describes repositioning in the region of the maxillary central incisors. Single-tooth osteotomy of one incisor was reported twice [18] [20], while repositioning of a dentoalveolar bone block consisting of both the right and left maxillary central incisor was reported once [21]. Moreover, dentoalveolar segmental osteotomy including an osseointegrated dental titanium implant has also been used for immediate repositioning of an infraoccluded single crown in the region of right central incisor [19].

Different techniques have been used to fixate the repositioned dentoalveolar segment [18]-[21]. In our case, we placed a bracket on the ankylosed tooth and ligated the mobilized tooth and dentoalveolar segment to the orthodontic appliance. Medeiros and al. used a similar technique [18], while Chae et al. additionally used a miniplate to fixate the apical part of the dentoalveolar segment in the correct position [20]. A prefabricated splint and a removable partial denture have also been used to stabilized the ankylosed tooth in the correct dental arch position [19] [21]. Moreover, autogenous bone graft has been used to fill the gap between the mobilized dentoalveolar segment and the maxilla [20] [21].

The follow-up time was not reported in all cases, but varied between 9 and 18 months, respectively [18]-[21]. The follow-up time in our case was 18 months and the functional and esthetic result seems to been in accordance with the previous published case reports.

A single-tooth osteotomy with immediate placement of the impacted and ankylosed tooth in correct dental arch position seems to be a good treatment modality in selected cases compared to other treatment solutions for impacted and ankylosed teeth. However, long-term studies with larger patient samples are needed before final conclusions can be provided about the treatment outcome of dentoalveolar segmental osteotomy combined with

Table 1. Case reports solely using dentoalveolar segmental osteotomy with immediate repositioning of the tooth.

\begin{tabular}{|c|c|c|c|c|c|c|}
\hline Patients & Tooth & Treatment & Complications & Follow-up & Conclusion & Author \\
\hline 1 & $\begin{array}{l}\text { Maxillary left } \\
\text { central incisor }\end{array}$ & $\begin{array}{l}\text { Dentoalveolar segmental } \\
\text { osteotomy with immediate } \\
\text { repositioning of the tooth. } \\
\text { Fixation to archwire }\end{array}$ & None & 18 months & $\begin{array}{l}\text { Dentoalveolar segmental } \\
\text { osteotomy is a viable surgical } \\
\text { procedure in treatment of an } \\
\text { ankylosed tooth }\end{array}$ & $\begin{array}{c}\text { Medeiros } \\
\text { et al. } 1997\end{array}$ \\
\hline 1 & $\begin{array}{l}\text { Titanium implant } \\
\text { in the region of } \\
\text { maxillary left } \\
\text { central incisor }\end{array}$ & $\begin{array}{l}\text { Dentoalveolar segmental } \\
\text { osteotomy with immediate } \\
\text { repositioning of the tooth. Fixated } \\
\text { with a removable partial denture }\end{array}$ & None & 9 months & $\begin{array}{l}\text { Treatment allows for } \\
\text { predictable result with } \\
\text { preservation of dental unit }\end{array}$ & $\begin{array}{c}\text { Martin } \\
\text { et al. } 1998\end{array}$ \\
\hline 1 & $\begin{array}{l}\text { Maxillary left } \\
\text { central incisor }\end{array}$ & $\begin{array}{l}\text { Dentoalveolar segmental } \\
\text { osteotomy with immediate } \\
\text { repositioning of the tooth. } \\
\text { Fixation to archwire and with } \\
\text { miniplate }\end{array}$ & None & 14 months & $\begin{array}{l}\text { Dentoalveolar segmental } \\
\text { osteotomy is a viable surgical } \\
\text { procedure in treatment of an } \\
\text { ankylosed tooth }\end{array}$ & $\begin{array}{c}\text { Chae et al. } \\
2012\end{array}$ \\
\hline 1 & $\begin{array}{l}\text { Maxillary right } \\
\text { and left central } \\
\text { incisor }\end{array}$ & $\begin{array}{l}\text { Dentoalveolar segmental } \\
\text { osteotomy with immediate } \\
\text { repositioning of the tooth. } \\
\text { Fixation with preformed splint }\end{array}$ & None & NR & $\begin{array}{l}\text { Dentoalveolar segmental } \\
\text { osteotomy is a viable surgical } \\
\text { procedure in treatment of an } \\
\text { ankylosed tooth }\end{array}$ & $\begin{array}{c}\text { You et al. } \\
2012\end{array}$ \\
\hline
\end{tabular}

NR: Not Reported. 
orthodontic treatment for impacted and ankylosed teeth.

Combined dentoalveolar segmental osteotomy and orthodontic distraction osteogenesis has previously been reported for impacted and ankylosed teeth with good functional and esthetic results [5]-[15] [17]. However, long-term studies involving larger patient samples are missing. Dentoalveolar distraction offers the advantage of being capable of enhancing both hard and soft tissue simultaneously and minimize the need for bone grafting of substantial osteotomy gab. Consequently, combined dentoalveolar segmental osteotomy and orthodontic distraction osteogenesis should be used for severely impacted and ankylosed teeth, especially in the esthetic zone. However, dentoalveolar segmental osteotomy followed by orthodontic distraction osteogenesis is time consuming, expensive, requires patient compliance and poses difficulties to control the vector of the dentoalveolar segment. Therefore, dentoalveolar segmental osteotomy with immediate repositioning of the tooth is recommended for minor impacted and ankylosed teeth while dentoalveolar segmental osteotomy followed by orthodontic distraction should be used for severely impacted ankylosed teeth in the esthetic zone.

\section{Conclusion}

Dentoalveolar segmental osteotomy with immediate repositioning of the impacted and ankylosed tooth in correct dental arch position seems to be a viable treatment option for minor impacted and ankylosed teeth.

\section{References}

[1] Biederman, W. (1962) Etiology and Treatment of Tooth Ankylosis. American Journal of Orthodontics, 48, 670-684. http://dx.doi.org/10.1016/0002-9416(62)90034-9

[2] Andreasen, J.O. (1980) A Time-Related Study of Periodontal Healing and Root Resorption Activity after Replantation of Mature Permanent Incisors in Monkeys. Swedish Dental Journal, 4, 101-110.

[3] Andreasen, J.O. (1980) Analysis of Pathogenesis and Topography of Replacement Resorption (Ankylosis) after Replantation of Mature Permanent Incisors in Monkeys. Swedish Dental Journal, 4, 231-240.

[4] Bishara, S.E. (1992) Impacted Maxillary Canines: A Review. American Journal of Orthodontics and Dentofacial Orthopedics, 101, 159-171. http://dx.doi.org/10.1016/0889-5406(92)70008-X

[5] Epker, B.N. and Paulus, P.J. (1978) Surgical-Orthodontic Correction of Adult Malocclusions: Single-Tooth DentoOsseous Osteotomies. American Journal of Orthodontics, 74, 551-563. http://dx.doi.org/10.1016/0002-9416(78)90031-3

[6] Cheng, C.Y., Zen, E.C. and Su, C.P. (1997) Surgical-Orthodontic Treatment of Ankylosis. Journal of Clinical Orthodontics, 31, 375-377.

[7] Isaacson, R.J., Strauss, R.A., Bridges-Poquis, A., Peluso, A.R. and Lindauer, S.J. (2001) Moving an Ankylosed Central Incisor Using Orthodontics, Surgery and Distraction Osteogenesis. The Angle Orthodontist, 71, 411-418.

[8] Kofod, T., Würtz, V. and Melsen, B. (2005) Treatment of an Ankylosed Central Incisor by Single Tooth DentoOsseous Osteotomy and a Simple Distraction Device. American Journal of Orthodontics and Dentofacial Orthopedics, 127, 72-80. http://dx.doi.org/10.1016/j.ajodo.2003.12.020

[9] Chang, H.Y., Chang, Y.L. and Chen, H.L. (2010) Treatment of a Severely Ankylosed Central Incisor and a Missing Lateral Incisor by Distraction Osteogenesis and Orthodontic Treatment. American Journal of Orthodontics and Dentofacial Orthopedics, 138, 829-838. http://dx.doi.org/10.1016/j.ajodo.2010.09.008

[10] Kim, Y., Park, S., Son, W., Kim, S., Kim, Y. and Mah, J. (2010) Treatment of an Ankylosed Maxillary Incisor by Intraoral Alveolar Bone Distraction Osteogenesis. American Journal of Orthodontics and Dentofacial Orthopedics, 138, 215-220. http://dx.doi.org/10.1016/j.ajodo.2008.07.024

[11] Im, J.J., Kye, M.K., Hwang, K.G. and Park, C.J. (2010) Miniscrew-Anchored Alveolar Distraction for the Treatment of the Ankylosed Maxillary Central Incisor. Dental Traumatology, 26, 285-288. http://dx.doi.org/10.1111/j.1600-9657.2010.00890.x

[12] Dolanmaz, D., Karaman, A.I., Pampu, A.A. and Topkara, A. (2010) Orthodontic Treatment of an Ankylosed Maxillary Central Incisor through Osteogenic Distraction. The Angle Orthodontist, 80, 391-395. http://dx.doi.org/10.2319/033009-182.1

[13] Ohkubo, K., Susami, T., Mori, Y., Nagahama, K., Takahashi, N., Saijo, H. and Takato T. (2011) Treatment of Ankylosed Maxillary Central Incisors by Single-tooth Dento-Osseous Osteotomy and Alveolar Bone Distraction. Oral Surgery, Oral Medicine, Oral Pathology, Oral Radiology, 111, 561-567. http://dx.doi.org/10.1016/j.tripleo.2010.06.026

[14] Uribe, F., Janakiraman, N., Cutrera, A., Schincaglia, G.P. and Nanda, R. (2013) Dentoalveolar Segmental Osteotomy for an Ankylosed Canine. Journal of Clinical Orthodontics, 47, 289-296. 
[15] Agabiti, I., Capparè, P., Gherlone, E.F., Mortellaro, C., Bruschi, G.B. and Crespi R. (2014) New Surgical Technique and Distraction Osteogenesis for Ankylosed Dental Movement. Journal of Craniofacial Surgery, 25, 828-830. http://dx.doi.org/10.1097/SCS.0000000000000737

[16] Rodrigues, D.B., Wolford, L.M., Figueiredo, L.M. and Adams, G.Q. (2014) Management of Ankylosed Maxillary Canine with Single-Tooth Osteotomy in Conjunction with Orthognathic Surgery. Journal of Oral and Maxillofacial Surgery, 72, 2419.e1-6. http://dx.doi.org/10.1016/j.joms.2014.07.016

[17] Senış1k, N.E., Koçer, G. and Kaya B.Ü. (2014) Ankylosed Maxillary Incisor with Severe Root Resorption Treated with a Single-Tooth Dento-Osseous Osteotomy, Vertical Alveolar Distraction Osteogenesis, and Mini-Implant Anchorage. American Journal of Orthodontics and Dentofacial Orthopedics, 146, 371-384. http://dx.doi.org/10.1016/j.ajodo.2013.10.026

[18] Medeiros, P.J. and Bezerra, A.R. (1997) Treatment of an Ankylosed Central Incisor by Single-Tooth Dento-Osseous Osteotomy. American Journal of Orthodontics and Dentofacial Orthopedics, 112, 496-501. http://dx.doi.org/10.1016/S0889-5406(97)70076-3

[19] Martin, R.J., Goupil, M.T. and Goldschmidt, M. (1998) Single-Implant Segmental Osteotomy: A Case Report. The International Journal of Oral \& Maxillofacial Implants, 13, 710-712.

[20] Chae, J.M. and Paeng, J.Y. (2012) Orthodontic Treatment of an Ankylosed Maxillary Central Incisor Through Single-Tooth Osteotomy by Using Interdental Space Regained from Microimplant Anchorage. American Journal of Orthodontics and Dentofacial Orthopedics, 141, e39-51. http://dx.doi.org/10.1016/j.ajodo.2011.06.046

[21] You, K.H, Min, Y.S. and Baik, H.S. (2012) Treatment of Ankylosed Maxillary Central Incisors by Segmental Osteotomy with Autogenous Bone Graft. American Journal of Orthodontics and Dentofacial Orthopedics, 141, 495-503. http://dx.doi.org/10.1016/j.ajodo.2010.06.029 